Acta vet. scand. $1974,15,454-456$.

Brief Communication

\title{
PERSISTENCE OF $\alpha$-TOCOPHEROL IN THE POST RUMEN DIGESTIVE TRACT OF THE RUMINANT
}

The poor deposition of $\alpha$-tocopherol (vitamin $E$ ) in body tissues and milk of animals is presumably due to factors operating either in the digestive tract or in the subsequent metabolism and excretion of this vitamin.

The present work is concerned about the persistency of $\alpha$ tocopherol in the guts of ruminants. In previous studies absorption of radioactive tocopherol was found to be as high as $40-$ $50 \%$ (Tikriti 1969) with lactating cows.

Experiments with rats have indicated that the absorption of dietary tocopherol is in the order of $50 \%$ (Peake et al. 1972). The digestibility of vitamin $\mathrm{E}$ may also be influenced by the nature of the dietary fat; for example the feeding of medium chain triglycerides improved the absorption in rats (Davies et al. 1972). Conflicting reports exist on the influence of unsaturated fats on the absorption of vitamin $\mathrm{E}$ in rats; both inhibitory (Weber et al. 1964) and non-inhibitory (Peake et al.) effects have been reported.

The approach of this study was to assay the faecal output of labelled tocopherol after its introduction (as a single dose) into the abomasum of a fistulated goat. Four experiments were conducted; in addition the distribution of radioactivity in faecal extracts was studied in three of these experiments.

Conditions were also varied in the way that different fats, in amounts of $1 \mathrm{~g}$, were infused through the abomasal fistula together with $10 \mathrm{mg}$ of the labelled vitamin $\mathrm{E}$ :

Experiment no.: 1. Without fat (control)

2. Hydrogenated marine fat

3. Safflower oil

4. Linoleic acid

The amounts of radioactivity were $300 \mu \mathrm{C}$ in experiments 1,2 and 3 and $150 \mu \mathrm{C}$ in experiment 4 . Faecal samples were collected morning and evening over a period of $60 \mathrm{hrs}$. after infusion. 
Each sample of faeces (each collection) was diluted with twice the amount of water and homogenized in a blender. Extracts of the faeces (10 g) were prepared and chromatographed as described elsewhere (Astrup et al. 1974) for the rumen incubations. It was found to be essential to protect the extract by the addition of antioxidant before concentration in the rotary evaporator. Hydroquinone was used at a concentration of 500 p.p.m. All animals were fed lucerne chaff and oat grain mixture $(1: 1 \mathrm{w} / \mathrm{w})$.

The faecal turn-out of radioactivity expressed as a percentage of the administered dose was $43 \%, 35 \%, 43 \%$ and $46 \%$ for experiments 1,2 and 3 and 4 , respectively. Thus, the apparent absorption was high (average of $58 \%$ for the four experiments and thereby confirms the results of Tikriti obtained with milking cows. Furthermore, there did not appear to be a marked effect of including fat with the infused tocopherol although hydrogenated marine fat (experiment 2) may have induced a slightly greater absorption of tocopherol than the safflower oil or linoleic acid (compare experiment 2 with experiments 3 and 4 ).

The faeces of the goat, when extracted in experiments $1-3$, appeared to give one single radioactive peak after TLC and scanning; this was identical to the original tocopherol and clearly shows that vitamin $\mathrm{E}$ is not metabolized or oxidized to any extent in the gut. Further studies on the deposition of vitamin $\mathrm{E}$ in meat and milk should, therefore, be concerned with its postabsorptive metabolic fate.

H. N. Astrup*, S. C. Mills, L. J. Cook and T. W. Scott

CSIRO,

Division of Animal Physiology,

Prospect, N.S.W., Australia.

\section{REFERENCES}

Astrup, H. N., S. C. Mills, L. J. Cook \& T. W. Scott: Stability of $\alpha$-tocopherol in rumen liquor of the sheep. Acta vet. scand. 1974, 15, $451-453$.

Davies, T., J. Kelleher, C. L. Smith, B. E. Walker \& M. S. Losowsky: Effect of therapeutic measures which alter fat absorption on the absorption of $\alpha$-tocopherol in the rat. J. Lab. clin. Med. 1972, $79,824-831$.

- Visiting fellow from the Institute of Animal Nutrition, Agricultural University, Ås, Norway. 
Peake, I. R., H. G. Windmueller \& J. G. Bieri: A comparison of the intestinal absorption, lymph and plasma transport, and tissue uptake of $\alpha$ - and $\gamma$-tocopherols in the rat. Biochim. biophys. Acta (Amst.) 1972, 260, 679-688.

Tikriti, H. H.: The Metabolism of Vitamin E by the Lactating Dairy Cow in Relation to Oxidized Flavour in Milk. Thesis, Univ. Maryland 1969, 124 pp.

Weber, F., H. Weiser \& O. Wiss: Bedarf an Vitamin E in Abhängigkeit von der Zufuhr an Linolsäure. (Requirement of vitamin $\mathrm{E}$ in relation to the supply of linoleic acid). 1964, 4, 245-253.

\section{(Received July 19, 1974).}

Reprints may be requested from: H. N. Astrup, Institute of Animal Nutrition, 1432 Ås-NLH, Norway. 